\title{
Red cell ABO incompatibility and production of tumour necrosis factor-alpha
}

\author{
R. D. Davenport, R. M. Strieter and S. L. Kunkel Department of Pathology and \\ Department of Internal Medicine. University of Michigan Medical School, Ann Arbor, Michigan
}

Received 11 January 1991; accepted for publication 6 April 1991

Summary. Tumour necrosis factor-alpha (TNF) is a major mediator of diverse pathophysiological events similar to those of haemolytic transfusion reactions (HTR), such as fever. intravascular coagulation and organ failure. However, the possible role of TNF in HTR has not been investigated. We have constructed an in vitro whole blood model of HTR to examine whether TNF may be produced in red cell $A B O$ incompatibility. TNF was observed in plasma, in a dose dependent manner, when $\mathrm{ABO}$ incompatible red cells were added, but not with compatible (group 0) cells. Plasma TNF levels were maximal at $2 \mathrm{~h}$, and declined to control levels by $24 \mathrm{~h}$. Haemolysis of incompatible red cells was accompanied by TNF production. Immune haemolysis induced TNF gene expression by buffy coat leucocytes, as determined by Northern blot analysis. Heat inactivation of plasma abolished TNF production, whereas prior treatment with interferongamma augmented the response. These results demonstrate that a major cytokine is produced in response to red cell incompatibility, and suggest that TNF may play a role in the pathogenesis of haemolytic transfusion reactions.
Knowledge of the pathophysiological events involved in haemolytic transfusion reactions (HTR) has lagged behind progress in our understanding of the inflammatory response, especially with respect to the role of cytokines. The cytokine tumour necrosis factor-alpha (TNF) has been shown to play a significant role in mediation of septic shock (Tracey \& Cerami, 1989). Biological activities attributed to TNF include: fever, shock, capillary leakage, leucocyte chemotaxis, activation of leucocytes and endothelial cells, and activation of the intrinsic coagulation cascade (Morimoto et al, 1989; Stephens et al, 1988; Meyer et al, 1988; Selby et al, 1987; Spriggs et al, 1987; Schleef et al, 1988; Berkow et al, 1987; Hoffman \& Weinberg, 1987; van der Poll et al, 1990). Septic shock shares many clinical characteristics with the syndrome of acute haemolytic transfusion reaction, including fever, shock, organ failure, intravascular coagulation, and death (Pineda et al, 1978). Previous investigations have shown that TNF is produced in whole blood, in vitro, in response to lipopolysaccharide challenge (Strieter et al, 1990). We therefore considered that TNF may be produced in whole blood during HTR, and, accordingly, developed a unique experimental model to investigate this question.

Correspondence: Dr R. D. Davenport, Department of Pathology, University of Michigan Hospitals 2G332/0054, Ann Arbor, Michigan 48109-0054, U.S.A.

\section{MATERIALS AND METHODS}

Blood. Whole blood (WB) was obtained from group $O$ normal volunteers drawn into heparin ( $50 \mathrm{USP} \mathrm{U} / \mathrm{ml}$ ). Red blood cells (RBC) were obtained from normal volunteer donors, drawn into CPDA-1 anticoagulant. The ABO types of $W B$ and $R B C$ were confirmed by standard haemagglutination techniques. Donors of WB lacked unexpected alloantibodies. RBC were washed three times with normal saline, and the buffy coat removed. WB was aliquoted into $5 \mathrm{ml}$ polypropylene tubes containing $2 \mathrm{ml}$ each. Washed packed RBC (haematocrit. $82 \pm 0.02$ ) were added in amounts indicated under Results. The tubes of blood were placed on a rocker in an incubator at $37^{\circ} \mathrm{C}$ with $5 \% \mathrm{CO}_{2}$ for times indicated below. In some experiments plasma was separated from $\mathrm{WB}$, heated to $56^{\circ} \mathrm{C}$ for $1 \mathrm{~h}$ to inactivate complement, and recombined with the cellular elements that had been washed three times in normal saline. In some experiments $100 \mathrm{U} / \mathrm{ml}$ interferongamma was added to WB and incubated for $4 \mathrm{~h}$ before RBC were added. When tubes were removed for the incubator. they were centrifuged for $5 \mathrm{~min}$ at $600 \mathrm{~g}$. The plasma was removed for TNF bioassay. The buffy coat was removed and placed into RBC lysing buffer for $2 \mathrm{~min}$. Leucocytes were recovered by centrifugation at $600 \mathrm{~g}$ for $3 \mathrm{~min}$, and RNA was extracted as below.

TNF bioassay. Plasma concentrations of TNF were measured using the WEHI 164 subclone 13 cell line, as previously described (Espevik \& Nissen Meyer, 1986). Briefly, samples 
A

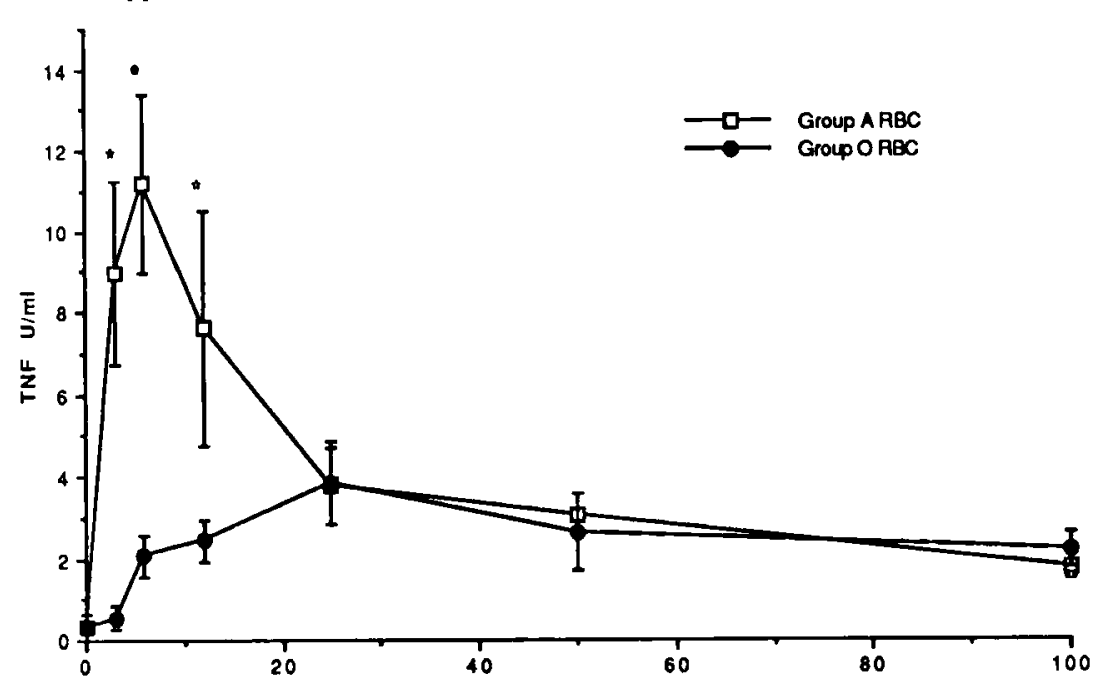

B

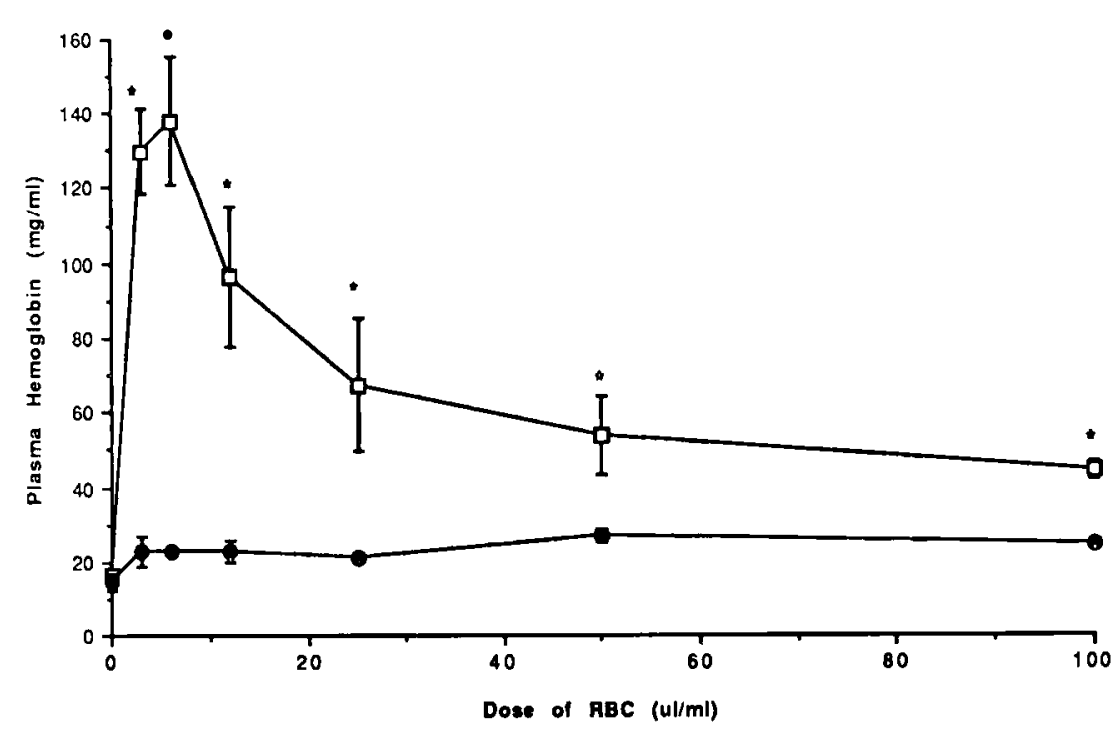

Fig 1. Mean ( \pm SEM) of plasma TNF (part A) and haemoglobin concentrations (part B) at $2 \mathrm{~h}$ as a function of dose of RBC. Significant differences between incompatible group $\mathrm{A} \mathrm{RBC}$ and compatible group $\mathrm{ORBC}(P<0.05)$ are indicated by *. Each point represents mean of three observations. Packed red cells were added to whole blood in amounts indicated. Plasma was separated from cells at $4 \mathrm{~h}$.

were serially diluted in flat-bottom 96-well microtitre plates (Costar. Cambridge, Mass.) using a multipipettor. Cells were resuspended in RPMI 1640 (Whitaker Biomedical Products, Whitaker, Calif.) with $10 \%$ fetal calf serum, $1 \mathrm{~mm} \mathrm{L-}$ glutamine, and $0.5 \mu \mathrm{g} / \mathrm{ml}$ actinomycin $\mathrm{D}$ to a concentration of $5 \times 10^{4} / \mathrm{ml}$ and added to the diluted samples $(0 \cdot 1 \mathrm{ml} /$ well $)$. Plates were allowed to incubate for $18-20 \mathrm{~h}$ at $37^{\circ} \mathrm{C}$ and $5 \%$ $\mathrm{CO}_{2} .20 \mu \mathrm{l}$ of MTT-tetrazolium $(5 \mathrm{mg} / \mathrm{ml}$, Sigma Chemical Co.) was added to each well and allowed to incubate an additional 4 h. $150 \mu \mathrm{l}$ of supernatant fluid was removed and $100 \mu \mathrm{l}$ of $0.04 \mathrm{~N} \mathrm{HCl} /$ isopropanol added to each well. The plates were stored overnight in the dark and then read on a microtitre plate reader (Bio-Tek Instruments, Inc., Winooski, Vt.) using a $550 \mathrm{~nm}$ filter. TNF units were calculated based on a standard curve generated with human recombinant TNF with a specific activity of 22 units/ng protein (Cetus Corp., Emeryville, Calif.).

Northern blot analysis. Total RNA was isolated from buffy coat leucocytes as previously described (Kunkel et al, 1988). Briefly, $3 \mathrm{ml}$ of $25 \mathrm{~nm}$ Tris, pH $8 \cdot 0$, containing $4 \cdot 2 \mathrm{M}$ guanidine isothiocyanate, $0.5 \%$ sarkosyl and $0.2 \mathrm{M} 2$ mercaptoethanol were added to each tube and homogenized. An equal volume of $100 \mathrm{~mm}$ Tris, $\mathrm{pH} 8 \cdot 0$, containing $10 \mathrm{~mm}$ EDTA and $1.0 \%$ SDS was added and the mixture extracted with chloroform-phenol and chloroform-isoamyl alcohol. The RNA was alcohol precipitated, and the pellet dissolved in $10 \mathrm{~mm}$ Tris/ $/ 1 \cdot 1 \mathrm{~mm}$ EDTA buffer with $0 \cdot 1 \%$ sarkosyl. The RNA was electrophoresed using formaldehyde/1\% agarose gels. The separated RNA was transblotted to nitrocellulose, baked, prehybridized, and hybridized with a 30-mer ${ }^{32} \mathrm{P}-5^{\prime}$ 


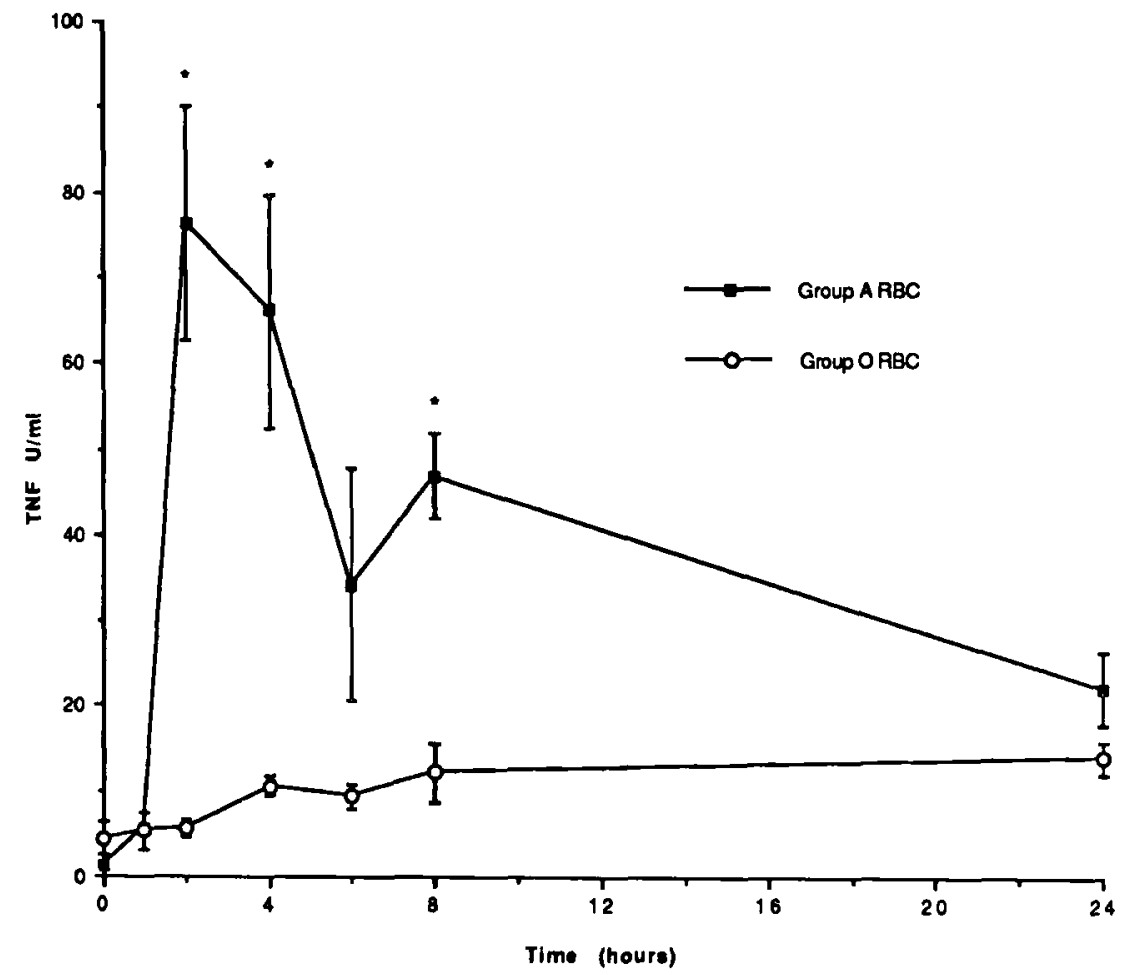

Fig 2. Time dependence of mean ( \pm SEM) plasma TNF following addition of $6 \mu \mathrm{l} \mathrm{RBC} / \mathrm{ml}$ WB. Significant differences between incompatible group A $\mathrm{RBC}$ and compatible group $\mathrm{O} \mathrm{RBC}(P<0 \cdot 05)$ are indicated by ${ }^{*}$. Each point represents mean of three observations.

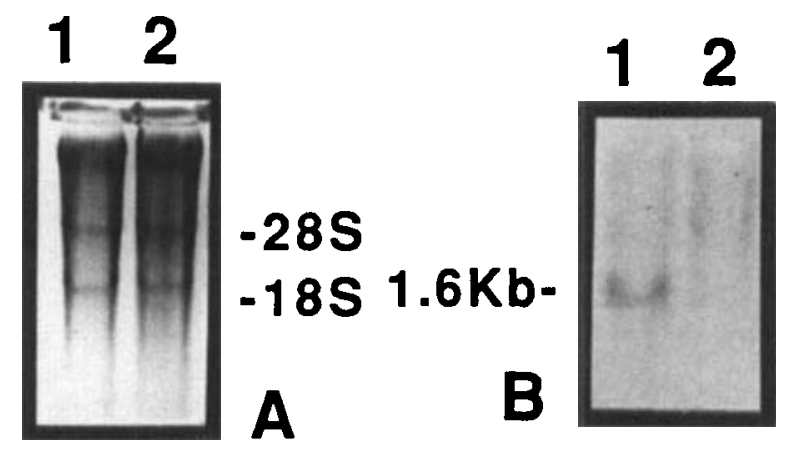

Fig 3. Northern blot of buffy coat mRNA isolated $1 \mathrm{~h}$ following addition of incompatible RBC (lane 1), or compatible RBC (lane 2) probed for TNF. Total RNA (part A) shows equal loading of lanes. Autoradiograph (part B) demonstrates $1.6 \mathrm{~kb}$ TNF mRNA with red cell incompatibility. Blood was pretreated with cycloheximide to inhibit protein synthesis (see Results).

end-labelled synthetic oligonucleotide probe for TNF, 5'ACA-AGC-ACC-GCC-TGG-AGC-CCT-GGG-GCC-CCC-3', antisense to nucleotides 150-179 of the TNF cDNA (Wang et al, 1985). Blots were washed and autoradiographed with intensifying screens. $40 \mu \mathrm{g}$ RNA was loaded per lane.

Plasma haemoglobin. Plasma haemoglobin concentrations were determined by the benzidine oxidation method as described (Crosby \& Furth, 1956).

Statistics. Paired data were compared by the Student $t$-test, as indicated in the figure legends.

\section{RESULTS}

TNF was produced in a dose and time dependent manner when incompatible $\mathrm{RBC}$ were added to group $\mathrm{O}$ whole blood. However, when compatible (group O) RBC were added, no TNF production occurred. Addition of group A, B or AB RBC caused TNF production that was indistinguishable between each of these three conditions. Incubation of RBC in plasma devoid of leucocytes resulted in haemolysis of incompatible $\mathrm{RBC}$, as expected, without TNF production.

The concentration of TNF in plasma was dependent on the amount of incompatible red cells added (Fig 1). The highest level was observed with $6 \mu \mathrm{l}$ of packed $\mathrm{RBC}$ per $\mathrm{ml}$ of WB. Statistically significant differences from group $O$ RBC $(P<0.05)$ were observed in the range of $3-12 \mu \mathrm{l} / \mathrm{ml} \mathrm{WB}$. The degree of haemolysis, as determined by plasma haemoglobin concentrations, paralleled the curve of plasma TNF production (Fig 1). The decrease in both haemolysis and TNF production with larger amounts of incompatible RBC most likely reflects the consumption of a critical intermediate. possibly a complement component, in this closed system.

Plasma TNF levels significantly above control were observed at $2 \mathrm{~h}$ after addition of incompatible RBC (Fig 2). At $24 \mathrm{~h}$ TNF levels were no different than with group $\mathrm{O}$ RBC. Haemolysis of incompatible $\mathrm{RBC}$ was complete at $2 \mathrm{~h}$. No haemolysis occurred with group $O R B C$. The optimal condition for TNF production was $6 \mu$ incompatible RBC per $1 \mathrm{ml}$ WB incubated $2 \mathrm{~h}$. Addition of lipopolysaccharide $10 \mu \mathrm{g} / \mathrm{ml}$ did not cause haemolysis, but did result in TNF production 

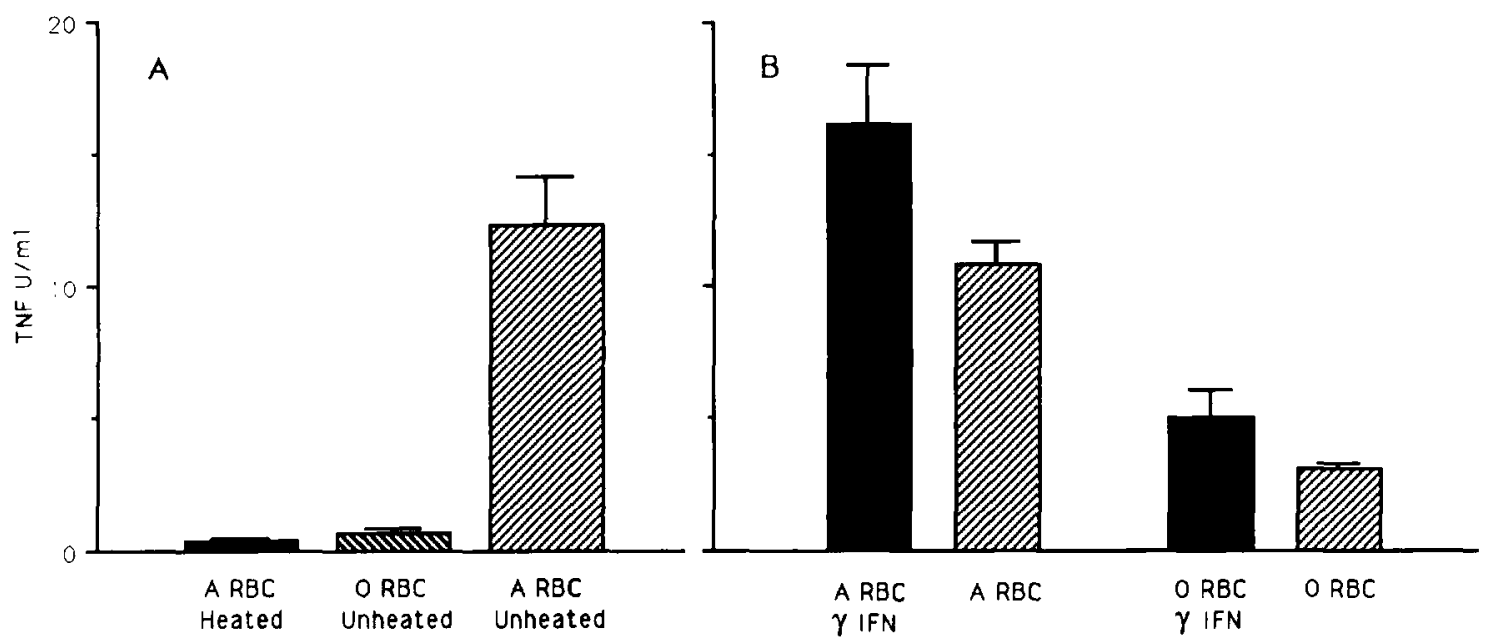

Fig 4. Effect of pretreatment conditions. Bars represent mean $( \pm \mathrm{SEM})$ of three observations $(12 \mu \mathrm{l} \mathrm{RBC} / \mathrm{ml}$ WB. incubated $4 \mathrm{~h})$. (A) Blood reconstituted with heat inactivated plasma (heated) did not respond to incompatible red cells. Significant differences $(P<0 \cdot 05)$ between blood reconstituted with normal plasma (unheated) stimulated with incompatible group A RBC and heated with A RBC or unheated with compatible $O$ RBC. (B) Blood pretreated with $\gamma$-interferon $(\gamma$ IFN) $4 \mathrm{~h}$ before addition of RBC showed enhanced response to incompatible $\mathrm{RBC}(P<0 \cdot 05)$. Difference in plasma TNF between $\gamma$ IFN treated and untreated blood with compatible RBC was not statistically significant.

$(1027 \pm 128 \mathrm{U} / \mathrm{ml}$ at $4 \mathrm{~h})$. Addition of recombinant human TNF $100 \mathrm{U} / \mathrm{ml}$ did not cause haemolysis.

To determine if immune haemolysis induced TNF gene transcription. buffy coat RNA was extracted and subjected to Northern blot analysis. TNF mRNA was barely detectable at the time of peak response, $2 \mathrm{~h}$ following $\mathrm{RBC}$ addition. However. TNF gene expression in response to incompatible $\mathrm{RBC}$ could be superinduced with $5 \mu \mathrm{g} / \mathrm{ml}$ cycloheximide added $1 \mathrm{~h}$ after $\mathrm{RBC}$ (Fig 3), indicating that as with lipopolysaccharide stimulation of mononuclear cells. TNF gene expression is most likely under the control of short-lived repressor proteins (Colart et al, 1986).

When plasma was separated from WB, heated to $56^{\circ} \mathrm{C}$ for 1 $h$ to inactivate complement and recombined with the washed cellular elements, both haemolysis and TNF production were abolished (Fig 4A). Agglutinating isoantibodies, however. were still present. This observation, in conjunction with the parallel dose relationship of haemolysis and TNF production, suggests that complement is a necessary intermediate in leucocyte activation due to $\mathrm{ABO}$ red cell incompatibility.

To determine if activation of WB with interferon-gamma altered TNF production, as with lipopolysaccharide stimulation (Collart et al, 1986; Beutler et al, 1986), WB was pretreated with $100 \mathrm{U} / \mathrm{ml}$ interferon-gamma $4 \mathrm{~h}$ before addition of $\mathrm{RBC}$, which resulted in a significant augmentation of TNF production in response to incompatible $\mathrm{RBC}$ (Fig 4B, $P<0 \cdot 05$ ). There was no statistically significant difference in TNF levels with interferon-gamma pretreatment and compatible RBC.

\section{DISCUSSION}

Present concepts of the pathogenesis of haemolytic transfusion reactions have focused primarily on the role of immune complexes in the activation of Hageman factor to trigger the coagulation and kinin systems, and the activation of the complement system to produce the anaphylotoxins C 3a and C5a, as well as red cell lysis (Goldfinger, 1977). However, few experimental data are available to support these hypotheses. Our results provide evidence that, in addition to these mediators, TNF may play a significant role in the pathological response to incompatible red cell transfusions. Several of the cardinal signs and symptoms of HTR may be mediated by TNF. Fever accompanied by rigours occurs upon infusion of recombinant human TNF at doses producing plasma levels similar to those observed in this model (Selby et al, 1987; Spriggs et al, 1987). Also, intravascular coagulation may be induced by TNF through activation of the intrinsic pathway, or by induction of tissue factor and plasminogen activator inhibitor in endothelial cells (Schleef et al, 1988; van der Poll et al, 1990). This latter effect of TNF may be of particular significance in HTR as evidenced by the histological similarities between the lesions caused by lipopolysaccharide and HTR.

Infusion of lipopolysaccharide, a potent stimulus for TNF, or of recombinant human TNF, results in acute renal tubular necrosis, intestinal infarction, and pulmonary haemorrhage with thrombosis and neutrophil accumulation, which is prevented by pretreatment with monoclonal antibody against TNF (Tracey et al, 1986). Experimental injection of incompatible blood produces similar histological lesions (Hardaway et al, 1956; McKay et al, 1956). Thrombi are found in pulmonary vessels with numerous leucocytes. Haemorrhagic necrosis occurs in the colon and small intestine. Acute tubular necrosis, haemoglobin casts, and thrombi are seen in the kidneys. Thrombosis dominates in animals that died shortly after red cell injection, whereas renal tubular necrosis and mucosal necrosis in the gastrointestinal tract are seen at later times.

Immune haemolysis has not been previously described as a stimulus for the production of TNF. The abolition of the response by heat treatment of plasma and the parallel 
relationship of haemolysis and TNF production strongly suggests that complement activation, and binding of complement products to monocyte surface receptors, is a necessary intermediate. Furthermore, augmentation of the response by pretreatment with interferon-gamma, which has also been observed with lipopolysaccharide stimulation of monocytes, as well as superinduction of TNF mRNA expression by cycloheximide suggest that common postreceptor pathways of TNF production are involved (Collart et al, 1986; Beutler $e t$ al, 1986). Although the role of cytokines in the pathophysiology of transfusion reactions remains to be completely elucidated, there is accumulating evidence that they play a role in producing the effects of incompatible red cell transfusion. Interleukin-8, another cytokine with chemotactic and activating effects on neutrophils, has also been shown to be produced in red cell incompatibility (Davenport et al, 1990).

\section{ACKNOWLEDGMENTS}

This study was supported in part by NIH grants HL 102401 . HL31593 and HL35276. Dr Kunkel is an Established Investigator of the American Heart Association. Dr Strieter is a RJR Nabisco Research Scholar. Pamela Lincoln and Donald Giacherio rendered technical assistance.

\section{REFERENCES}

Berkow, R.L., Wang, D., Larrick, J.W., Dodson, R.W. \& Howard, T.H. (1987) Enhancement of neutrophil superoxide production by preincubation with recombinant human tumor necrosis factor. Journal of Immunology. 139. 3783-3791.

Beutler. B., Tkacenko, V., Milsark. I., Krochin. N. \& Cerami, A.J. (1986) Effect of $\gamma$ interferon on cachectin expression by mononuclear phagocytes. Reversal of the $1 \mathbf{p s}^{\mathbf{d}}$ (endotoxin resistance) phenotype. Journal of Experimental Medicine, 164, 1791-1796.

Collart, M.A., Belin, D., Vassalli, J.D., de Kossodo, S. \& Vassalli, P.J. (1986) $\gamma$ interferon enhances macrophage transcription of the tumor necrosis factor/cachectin, interleukin 1, and urokinase genes, which are controlled by short-lived repressors. Journal of Experimental Medicine, 164, 2113-2118.

Crosby, W. \& Furth. F. (1956) A modification of the benzidine method for measurement of hemoglobin in plasma and urine. Blood, 11, 380-383.

Davenport, R.D., Strieter, R.M.. Standiford, T.J. \& Kunkel, S.L. (1990) Interleukin-8 production in red cell incompatibility. Blood, 76, 2439-2442.

Espevik, T. \& Nissen Meyer, J. (1986) A highly sensitive cell line, WEHI 164 clone 13, for measuring cytotoxic factor/tumor necrosis factor from human monocytes. Journal of Immunologic Methods, 95, 99-105.

Goldfinger, D. (1977) Acute hemolytic transfusion reactions. A fresh look at pathogenesis and considerations regarding therapy. Transfusion, 17, 85-98.

Hardaway, R.M., McKay, D.G., Wahle, G.H., Tartlock, D.E. \& Edelstein, R. (1956) Pathologic study of intravascular coagulation following incompatible blood transfusion in dogs. I. Intravenous injection of incompatible blood. American Journal of Surgery, 91, 24-31.

Hoffman, M. \& Weinberg. J.B. (1987) Tumor necrosis factor-alpha induces increased hydrogen peroxide production and $\mathrm{Fc}$ receptor expression, but not increased Ia antigen expression by peritoneal macrophages. Journal of Leukocyte Biology. 42, 704-707.

Kunkel, S.L., Spengler. M.. May. M.A., Spengler, R., Larrick, J. \& Remick. D. (1988) Prostaglandin E2 regulates macrophagederived tumor necrosis factor gene expression. Journal of Biological Chemistry. 263, 5380-5384.

McKay, D.G., Hardaway, R.M., Wahle. G.H., Hall, R.M. \& Burns, R. (1956) Pathologic study of intravascular coagulation following incompatible blood transfusion in dogs. II. Intra-aortic injection of incompatible blood. American Journal of Surgery. 91, 32-40.

Meyer. J.D., Yurt, R.W., Duhaney, R., Hesse, D.G., Tracey, K.J., Fong. Y.M., Verma, M., Shires, G.T., Dineen, P., Lowry, S.F. \& Davis. J.M. (1988) Tumor necrosis factor-enhanced leukorene B4 generation and chemotaxis in human neutrophils. Archives of Surgery, 123, 1454-1458.

Morimoto, A., Sakata, Y., Watanabe, T. \& Murakami, N. (1989) Characteristics of fever and acute-phase response induced in rabbits by IL- 1 and TNF. American Journal of Physiology, 256, R 35 41.

Pineda, A.A., Brzica, S.M., Jr \& Taswell, H.G. (1978) Hemolytic transfusion reactions. Recent experience in a large blood bank. Mayo Clinical Proceedings, 53, 378-390.

Schleef, R.R., Bevilacqua, M.P., Sawdey, M., Gimbrone, M.A., Jr \& Loskutoff, D.J. (1988) Cytokine activation of vascular endothelium. Effects on tissue-type plasminogen activator and type 1 plasminogen activator inhibitor. Journal of Biological Chemistry. 25, 5797-5803.

Selby, P., Hobbs, S., Viner, C., Jackson, E., Jones, A., Newell, D., Calvert, A.H., McElwain, T., Fearon, K., Humphreys, J. \& Shiga, T. (1987) Tumour necrosis factor in man: clinical and biological observations. British Journal of Cancer, 56, 803-808.

Spriggs, D.R., Sherman, M.L., Frei, E., 3rd \& Kufe, D.W. (1987) Clinical studies with tumour necrosis factor. Ciba Foundation Symposium, 131, 206-227.

Stephens, K.E., Ishizaka. A., Larrick, J.W. \& Raffin. T.A. (1988) Tumor necrosis factor causes increased pulmonary permeability and edema. Comparison to septic acute lung injury. American Reviews of Respiratory Disease. 137, 1364-1370.

Strieter, R.M.. Remick, D.G.. Ham. J.M.. Colletti, L.M., Lynch. J.P., 3rd \& Kunkel, S.L. (1990) Tumor necrosis factor-alpha gene expression in human whole blood. Journal of Leukocyte Biology. 47. 356-370.

Tracey, K.J., Beutler, B., Lowry, S.F, Merryweather, I., Wolpe, S. Milsark, I.W., Hariri, R.J., Fahey, T.J., Zentalla, A., Albert, J.D., Shires, G.T. \& Cerami, A. (1986) Shock and tissue injury induced by recombinant human cachectin. Science, 234, 470-474.

Tracey, K.J. \& Cerami, A. (1989) Cachectin/tumor necrosis factor and other cytokines in infectious disease. Current Opinion in Immunology. 1, 454-461.

van der Poll, T., Buller, H.R., ten Cate, H., Wortel, C.H., Bauer, K.A., van Deventer, S.J.H., Hack, C.E. Sauerwein. H.P., Rosenberg. R.D. $\&$ ten Cate. J.W. (1990) Activation of coagulation after administration of tumor necrosis factor to normal subjects. New England Journal of Medicine. 322, 1622-1627.

Wang, A.M., Creasey. A.A., Ladner, M.B., Lin. L.S., Strickler. J., Van Arsdell, J.N., Yamamoto, R. \& Mark, D.F. (1985) Molecular cloning of the complementary DNA for human tumor necrosis factor. Science, 228, 149-154. 